\title{
Quantitative measurements of joint mobility in adolescents
}

\author{
JEREMY C. T. FAIRBANK, ${ }^{1}$ PAUL B. PYNSENT ${ }^{2}$ AND HUGH PHILLIPS ${ }^{3}$ \\ From ${ }^{1}$ St Bartholemew's Hospital, West Smithfield, London EC1A $7 \mathrm{BE},{ }^{2}$ West Norwich Hospital, Norwich, \\ NR2 $3 T U$, and ${ }^{3}$ Norfolk and Norfolk Hospital, Norwich, NR1 3SR
}

SUMMARY Six measurements of joint mobility were made in a group of 446 normal adolescents. A method of measuring hip and knee rotation is presented. All these data are normally distributed, and would suggest that joint hypermobility lies at the end of the normal spectrum. There was a weak but significant correlation between each of the different measures of joint mobility except elbow hyperextention. Criteria for joint laxity are discussed in this age group, and the importance of quantitative techniques of measuring joint mobility are emphasised.

Joint laxity has been of interest to clinicians since the early part of this century. ${ }^{1}$ There is no generally agreed method of assessment, although most authors have used versions of Carter and Wilkinson's 5 tests. Their measurements were designed for young children. In older children and adults genu recurvatum and ankle hyperflexion are more difficult to measure.

Carter and Wikinson used a point scoring system to indicate whether or not excessive joint laxity existed. Derivatives of this system have been advocated by Beighton et al. ${ }^{3}$ and Bird et al.., ${ }^{4}$ but all have the disadvantage of using arbitrary criteria. In a study of adolescent knee and back pain ${ }^{56}$ we found difficulties

Accepted for publication 9 March 1983.

Correspondence to $\mathrm{Mr}$ J. C. T. Fairbank, FRCS.

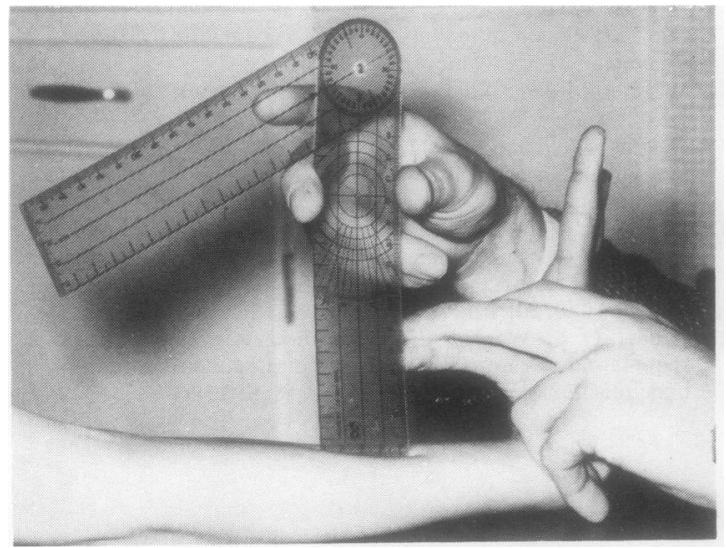

Fig. 1 Right thumb abduction. Perpendicular distance from tip of nail to volar aspect of forearm. in using Carter and Wilkinson's criteria in older children to establish whether or not joint laxity existed.

This paper presents a quantitative assessment of 3

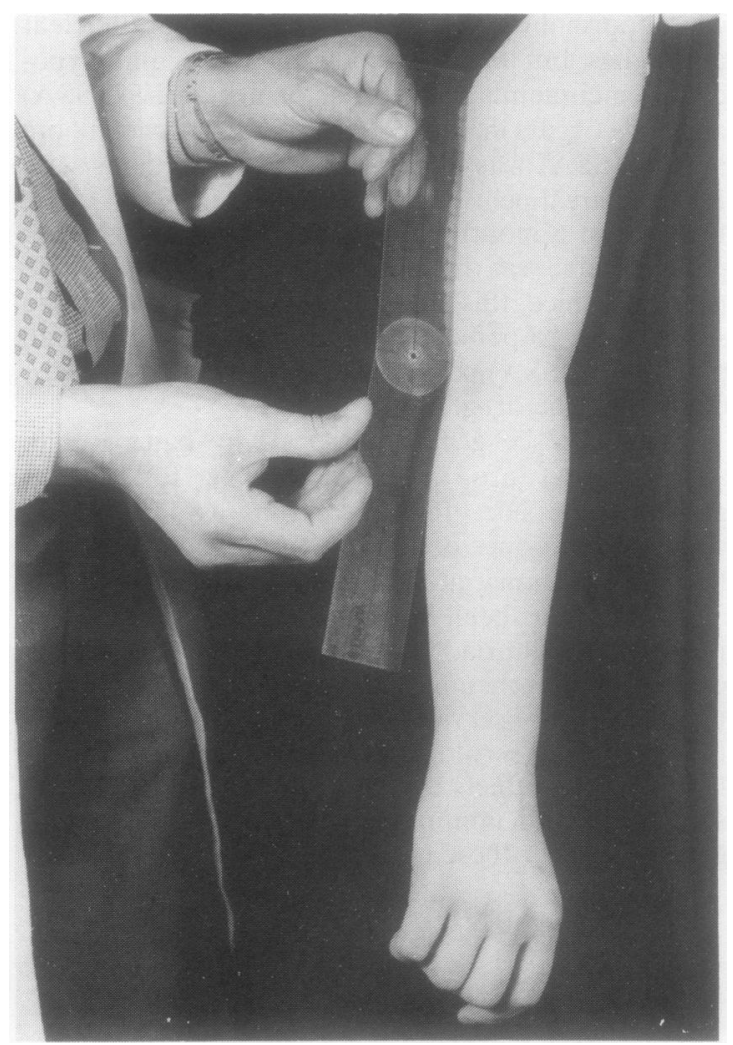

Fig. 2 Right elbow extension. 
upper and 3 lower limb measures of joint mobility in 446 adolescent schoolchildren. We describe methods of measuring femoral rotation at the hip and tibial rotation at the knee.

\section{Material and Methods}

The investigation was made in a comprehensive school of 1850 pupils during the course of one week. The subjects were those attending biology lessons and were considered a random selection of the pupils at the school. The signs of upper limb mobility were assessed by one observer on the right arm of each subject. The measurements of lower limb mobility were assessed by sixth formers under the supervision of one of the authors. Twenty nine pupils were

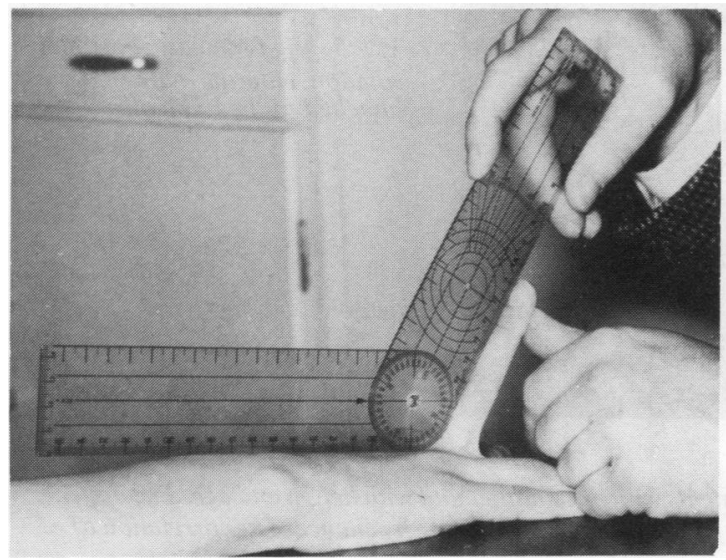

Fig. 3 Right middle finger extension. selected by a random number table for repeat measurement, and these results were assessed by linear regression analysis.

The measurements of joint mobility were:

(1) Right thumb abduction and wrist flexion, measuring the perpendicular distance from the tip of the thumb nail to the volar aspect of the forearm (Fig. 1).

(2) Right elbow extension, measuring the angle between the extensor aspects of the arm above and below the elbow with a goniometer (Fig. 2).

(3) Right middle finger extension, measuring the angle above and below the extensor aspect of the metacarpophalangeal joint with a goniometer (Fig. 3).

(4) The total rotation with the right hip joint held in extension. The pupil lay prone in a jig with the knee flexed to $90^{\circ}$. The angle through which the leg could be moved was measured with a large vertical protractor (Fig. 4).

(5) The total rotation of the right tibia at the knee,

Table 1 Sex and age distribution of the sample

\begin{tabular}{lccc}
\hline Age (years) & Males & Females & Total \\
\hline 13 & 65 & 40 & 105 \\
14 & 52 & 47 & 99 \\
15 & 51 & 70 & 121 \\
16 & 24 & 36 & 60 \\
17 & 35 & 26 & 61 \\
Totals & 227 & 219 & 446 \\
\hline
\end{tabular}

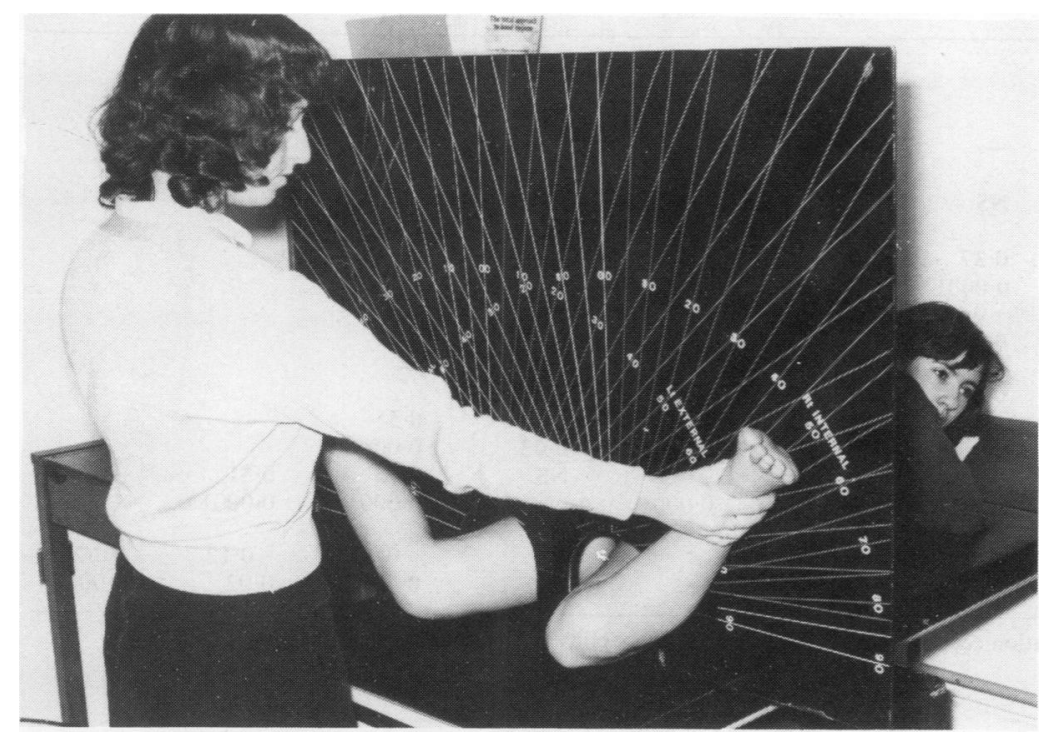

Fig. 4 Jig for measuring hip rotation. 
with the joint flexed to $90^{\circ}$. This was measured in the same position as (4), but in this case a pointer was attached to the malleoli and the rotation recorded against a horizontal protractor (Fig. 5).

(6) Knee extension was taken as the angle between the lines joining the anterior superior spine and the front of the right patella, and that joining the patella and the front of the ankle joint. These points were measured with a vector stereograph (for further details see Pynsent et al. ${ }^{7}$ and Fairbank et al. ${ }^{6}$

The data were analysed by Student's $t$ test, Spearman rank correlation, and linear regression.

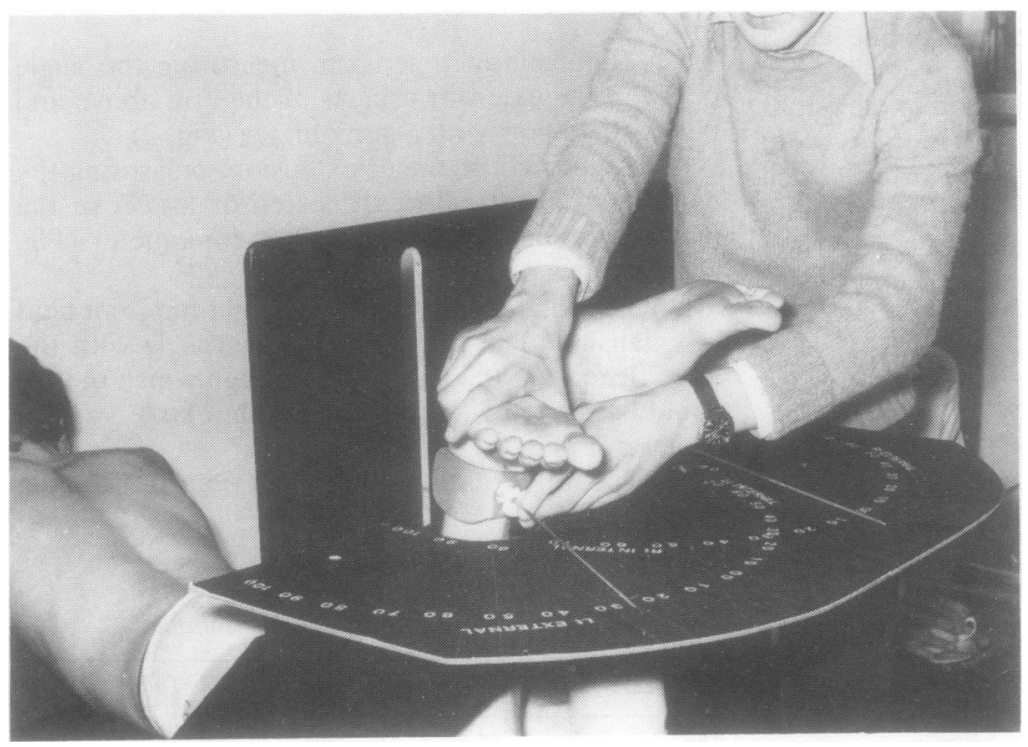

Fig. 5 Jig for measuring tibial rotation. Note the marker attached to the malleoll.

Table 2 Spearman rank correlation of joint mobility measurements with one another and with height and age. The upper figure is the correlation coefficient and the lower the probability of this correlation occurring by chance. The correlation of the joint mobility score with height, age and weight is shown

\begin{tabular}{|c|c|c|c|c|c|c|c|c|c|}
\hline & Thumb & Elbow & Finger & $\begin{array}{l}\text { Hip } \\
\text { rotat. }\end{array}$ & $\begin{array}{l}\text { Tibial } \\
\text { rotat. }\end{array}$ & $\begin{array}{l}\text { Knee } \\
\text { ext. }\end{array}$ & Height & Age & Weight \\
\hline Thumb & - & & & & & & & & \\
\hline Elbow & $\begin{array}{l}-0 \cdot 19^{*} \\
0 \cdot 0001^{*}\end{array}$ & - & & & & & & & \\
\hline Finger & $\begin{array}{l}-0.36 \\
0.0001\end{array}$ & NS & - & & & & - & & \\
\hline $\begin{array}{l}\text { Hip } \\
\text { rotat. }\end{array}$ & $\begin{array}{c}-0 \cdot 24 \\
0 \cdot 0001\end{array}$ & NS & NS & - & & & & & \\
\hline Tibial & -0.34 & $-0 \cdot 1$ & 0.37 & $0 \cdot 25$ & - & & & & \\
\hline $\begin{array}{l}\text { rotat. } \\
\text { Knee }\end{array}$ & $\begin{array}{l}0.0001 \\
0.28\end{array}$ & $\begin{array}{l}0.04 \\
-0.2\end{array}$ & 0.0001 & 0.0001 & & & & & \\
\hline $\begin{array}{l}\text { Knee } \\
\text { ext. }\end{array}$ & $\begin{array}{l}0 \cdot 28 \\
0.001\end{array}$ & $\begin{array}{l}-0 \cdot 2 \\
0.0002\end{array}$ & $\begin{array}{l}-0 \cdot 16 \\
0.0003\end{array}$ & $\begin{array}{l}-0.19 \\
0.0003\end{array}$ & NS & - & & & \\
\hline Height & $\begin{array}{l}0 \cdot 19 \\
0 \cdot 0001\end{array}$ & $\begin{array}{l}0.1 \\
0.04\end{array}$ & $\begin{array}{l}-0.22 \\
0.0001\end{array}$ & $\begin{array}{l}-0.17 \\
0.002\end{array}$ & $\begin{array}{c}-0.21 \\
0.0001\end{array}$ & NS & - & & \\
\hline Age & NS & $\begin{array}{l}0 \cdot 2^{*} \\
0 \cdot 0001\end{array}$ & $\begin{array}{l}-0.15 \\
0.002\end{array}$ & $\begin{array}{l}-0 \cdot 16 \\
0.0006\end{array}$ & $\begin{array}{l}0.26 \\
0.0001\end{array}$ & $\begin{array}{l}0.11 \\
0.03\end{array}$ & $\begin{array}{l}0 \cdot 5 \\
0 \cdot 0001\end{array}$ & - & \\
\hline Weight & $\begin{array}{l}0 \cdot 14 \\
0 \cdot 0003\end{array}$ & $\begin{array}{l}0 \cdot 16 \\
0 \cdot 0008\end{array}$ & $\begin{array}{l}-0.14 \\
0.0006\end{array}$ & $\begin{array}{l}-0.27 \\
0.0007\end{array}$ & $\begin{array}{l}-0.3 \\
0.0001\end{array}$ & NS & $\begin{array}{l}0.75 \\
0.0001\end{array}$ & $\begin{array}{l}0.51 \\
0.0001\end{array}$ & - \\
\hline $\begin{array}{l}\text { Joint } \\
\text { mobility } \\
\text { score }{ }^{\dagger}\end{array}$ & - & - & - & - & - & - & $\begin{array}{l}-0.23 \\
0.0001\end{array}$ & $\begin{array}{l}-0.12 \\
0.02\end{array}$ & $\begin{array}{c}-0 \cdot 23 \\
0 \cdot 0001\end{array}$ \\
\hline
\end{tabular}

In each case the upper figure is the correlation coefficient and the lower the probability that the data are random.

NS is not significant at the 0.05 level.

* Reverse of expected correlation.

+For derivation see Fig. 7. 


\section{Results}

Four hundred and forty-six pupils, comprising 219 girls and 227 boys ranging from 13 to 17 years of age, were studied (Table 1). The range and distribution of each measurement is shown in Figs 6a-f. All were normally distributed. There were low but significant

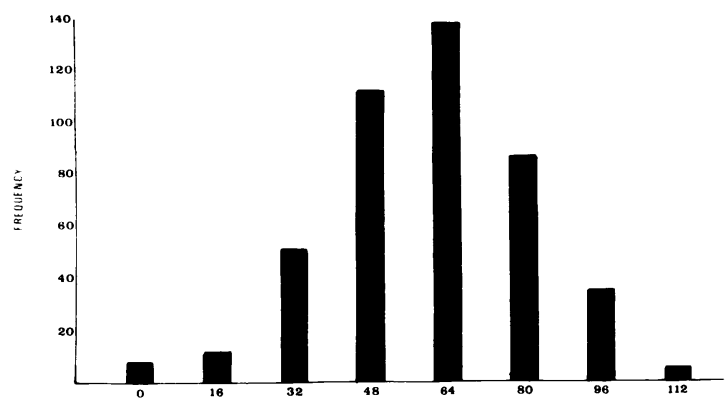

Fig. 6a

Fig. 6 (a) Distribution of thumb abduction. Note that 0 is the maximum that is possible. Distance in millimetres. (b) Distribution of elbow extension. Note that $0^{\circ}$ is neutral. $-5^{\circ}$ is hyperextension, $+5^{\circ}$ is fixed flexion. (c) Distribution of finger extension. (d) Distribution of femoral rotation. (e) Distribution of tibial rotation.

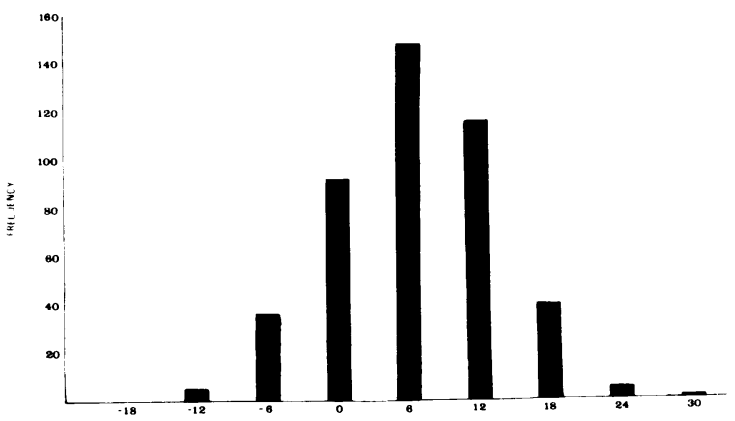

Fig. $6 \mathrm{~b}$

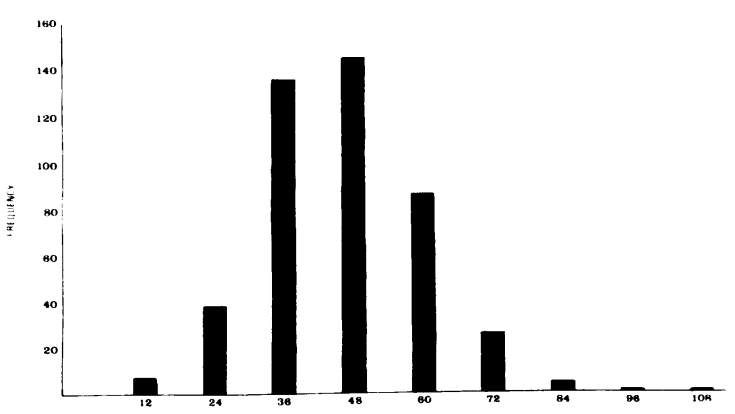

Fig. 6c

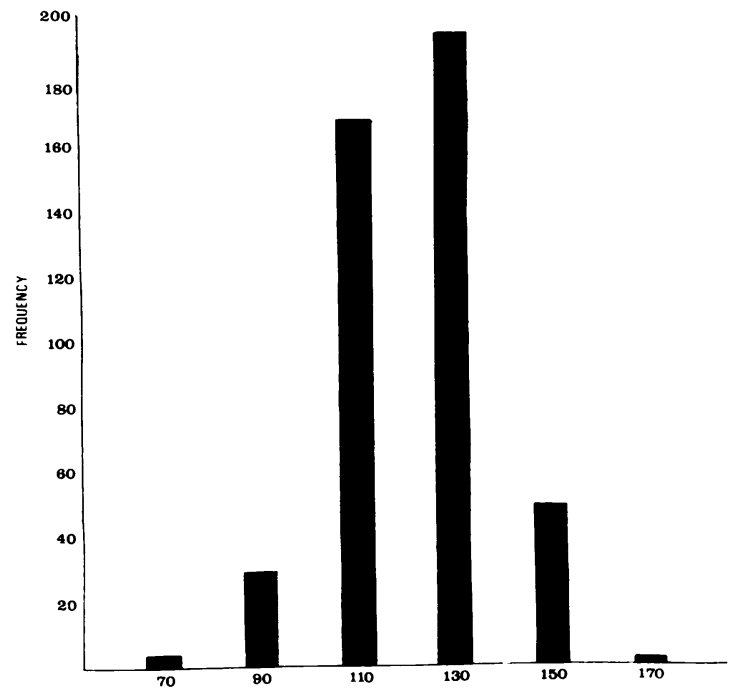

femoral Rotation 101

Fig. 6d

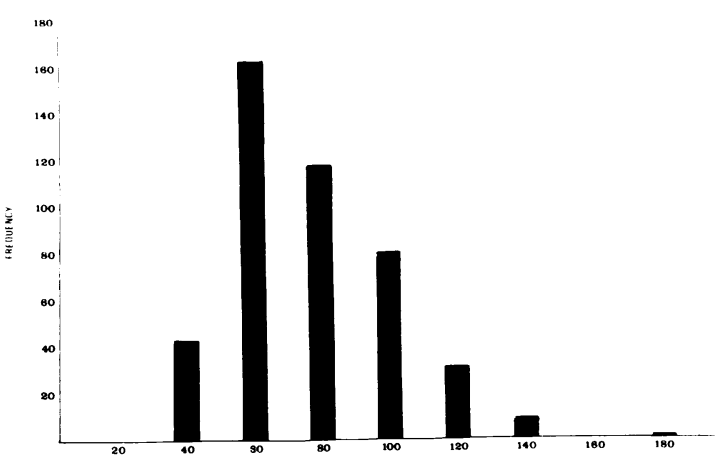

Fig. $6 \mathrm{e}$

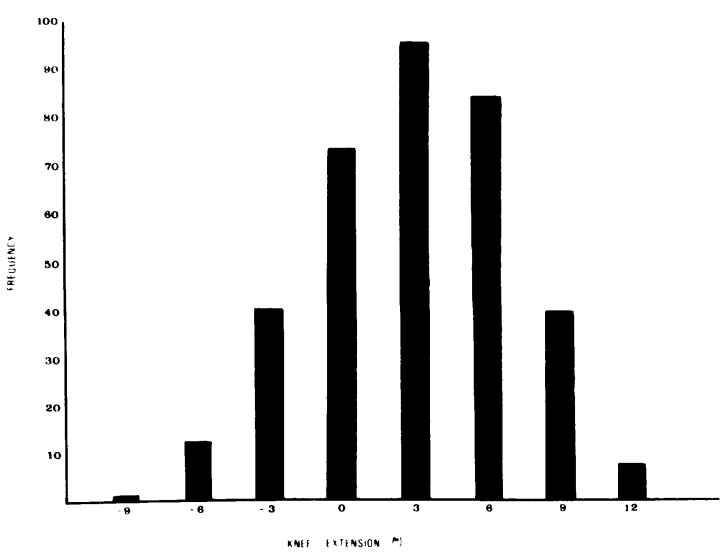

Fig. $6 f$ 
correlation coefficients between each measurement except for elbow extension (Table 2). In some joints mobility was negatively correlated with age (Table 2).

There were small and in some cases significant differences between the joint mobility of males and females, with females tending to be more lax (Table 3).

A scoring system was prepared on the basis of Carter and Wilkinson's system ${ }^{2}$ except that our criteria are based on the mean mobility plus 2 standard deviations. These are compared with the criteria of Carter and Wilkinson ${ }^{2}$ and Beighton et al. ${ }^{3}$ in Table 4. This score was normally distributed in this population (Fig. 7) and showed a clear negative correlation with height and age (Table 2) and that females were more lax than males. The reliability of the various measurements is shown by comparison with repeat measurements using a linear regression analysis (Table 5).

Table 3 Comparison of upper and lower limb joint mobility in 227 males and 219 females

\begin{tabular}{|c|c|c|c|c|c|}
\hline \multirow{4}{*}{$\begin{array}{l}\mathbf{R} \text { thumb abduction } \\
\mathbf{R} \text { elbow extension } \\
\mathbf{R} \text { middle finger extension } \\
\mathbf{R} \text { tibia }\end{array}$} & \multicolumn{2}{|c|}{$\begin{array}{l}218 \text { Females } \\
\text { mean } \pm s d\end{array}$} & \multicolumn{2}{|c|}{$\begin{array}{l}227 \text { Males } \\
\text { mean } \pm s d\end{array}$} & \multirow{2}{*}{$\begin{array}{l}\begin{array}{l}t \text { test } \\
\text { probability }\end{array} \\
\mathrm{p}<0.0001\end{array}$} \\
\hline & $54 \mathrm{~mm}$ & \pm 19 & $67 \mathrm{~mm}$ & \pm 20 & \\
\hline & & \pm 6 & & \pm 7 & $\mathrm{p}<0.0001$ \\
\hline & $48^{\circ}$ & \pm 13 & $45^{\circ}$ & \pm 13 & NS \\
\hline External rotation & $43^{\circ}$ & \pm 13 & $40^{\circ}$ & \pm 11 & $p<0.008$ \\
\hline Total rotation & $80^{\circ}$ & \pm 24 & $75^{\circ}$ & \pm 22 & $\mathrm{p}<0.02$ \\
\hline \multicolumn{6}{|l|}{ L tibia } \\
\hline External rotation & $44^{\circ}$ & \pm 12 & $38^{\circ}$ & \pm 12 & $\mathrm{p}<0.0001$ \\
\hline Internal rotation & $37^{\circ}$ & \pm 13 & $35^{\circ}$ & \pm 13 & NS \\
\hline Total rotation & $81^{\circ}$ & \pm 21 & $73^{\circ}$ & \pm 22 & $\mathrm{p}<0.0001$ \\
\hline \multicolumn{6}{|l|}{$\mathbf{R}$ femur } \\
\hline External rotation & $63^{\circ}$ & \pm 9 & $67^{\circ}$ & \pm 11 & $\mathrm{p}<0.0001$ \\
\hline Internal rotation & $63^{\circ}$ & \pm 10 & $56^{\circ}$ & \pm 11 & $\mathrm{p}<0.0001$ \\
\hline \multicolumn{6}{|l|}{ L femur } \\
\hline External rotation & $63^{\circ}$ & \pm 9 & $68^{\circ}$ & \pm 10 & $\mathrm{p}<0.0001$ \\
\hline Internal rotation & $63^{\circ}$ & \pm 11 & $59^{\circ}$ & \pm 11 & $p<0.0001$ \\
\hline Total rotation & $126^{\circ}$ & \pm 16 & $127^{\circ}$ & \pm 16 & NS \\
\hline $\mathbf{R}$ knee extension & $2^{\circ}$ & \pm 4 & $4^{\circ}$ & \pm 4 & $p<0.0001$ \\
\hline L knee extension & $1^{\circ}$ & \pm 5 & $4^{\circ}$ & \pm 4 & $\mathrm{p}<0.0001$ \\
\hline
\end{tabular}

$\mathrm{R}=$ right. $\quad \mathrm{L}=$ left. $\quad$ For NS see Table 1.

Table 4 Comparison of criteria of joint mobility between this study and those of Carter and Wilkinson ${ }^{2}$ and Beighton et al. $^{3}$

\begin{tabular}{|c|c|c|c|c|c|c|}
\hline & Mean & $\pm 1 S D$ & $\pm 2 S D$ & & $\begin{array}{l}\text { Carter and } \\
\text { Wilkinson }^{2}\end{array}$ & $\begin{array}{l}\text { Beighton } \\
\text { et al. }\end{array}$ \\
\hline Thumb abduction & $61 \mathrm{~mm}$ & $\begin{array}{l}41 \mathrm{~mm} \\
81 \mathrm{~mm}\end{array}$ & $\begin{array}{l}21 \mathrm{~mm} \\
101 \mathrm{~mm}\end{array}$ & $\begin{array}{l}\text { Lax } \\
\text { stiff }\end{array}$ & $0 \mathrm{~mm}$ & $0 \mathrm{~mm}$ \\
\hline Elbow extension & $7^{\circ}$ & $\begin{array}{l}0^{\circ} \\
14^{\circ}\end{array}$ & $\begin{array}{l}-7^{\circ} \\
21^{\circ}\end{array}$ & $\begin{array}{l}\text { Lax } \\
\text { Stiff }\end{array}$ & $-10^{\circ}$ & $-10^{\circ}$ \\
\hline $\begin{array}{l}\text { Middle finger } \\
\text { extension }\end{array}$ & $47^{\circ}$ & $61^{\circ}$ & $\begin{array}{l}75^{\circ} \\
19^{\circ}\end{array}$ & $\begin{array}{l}\text { Lax } \\
\text { Stiff }\end{array}$ & $\left(90^{\circ}\right)^{*}$ & $\left(90^{\circ}\right) \dagger$ \\
\hline $\begin{array}{l}\text { Right femoral } \\
\text { rotation }\end{array}$ & $125^{\circ}$ & $\begin{array}{l}140^{\circ} \\
110^{\circ}\end{array}$ & $\begin{array}{l}155^{\circ} \\
95^{\circ}\end{array}$ & $\begin{array}{l}\text { Lax } \\
\text { Stiff }\end{array}$ & - & - \\
\hline $\begin{array}{l}\text { Right tibial } \\
\text { rotation }\end{array}$ & $79^{\circ}$ & $\begin{array}{l}103^{\circ} \\
55^{\circ}\end{array}$ & $\begin{array}{l}127^{\circ} \\
30^{\circ}\end{array}$ & $\begin{array}{l}\text { Lax } \\
\text { Stiff }\end{array}$ & - & - \\
\hline Knee extension & $3^{\circ}$ & $\begin{array}{l}-1^{\circ} \\
+7^{\circ}\end{array}$ & $\begin{array}{l}-5^{\circ} \\
+11^{\circ}\end{array}$ & $\begin{array}{l}\text { Lax } \\
\text { Stiff }\end{array}$ & $0^{\circ}$ & $-10^{\circ}$ \\
\hline
\end{tabular}

* Middle finger parallel with the dorsum of forearm

+ Little finger used. 


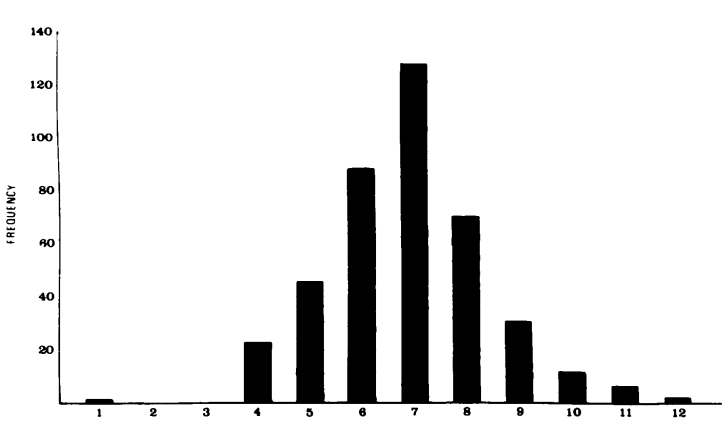

TOTAL LAXITY SCORE

Fig. 7 Distribution of joint laxity scores in whole sample. Each of 6 measures of joint mobility is scored for either 'stiff $=0(>2 S D$ of mean, 'neutral' $=1(<2 S D$ of mean), or 'lax' = 2 (>2 SD ofmean) to a maximum score of 12 for each individual.

Table 5 Assessment of repeated measurements in 29 randomly selected subjects. A regression line was fitted by least squares through the original and repeated data. $p$ is the probability that the data are random. Perfectly repeatable data would have a slope of 1

\begin{tabular}{lll}
\hline Measurement & Slope & $p$ \\
\hline Thumb abduction & 0.82 & 0.001 \\
Elbow extension & 0.89 & 0.001 \\
Finger extension & 0.80 & 0.001 \\
Femoral rotation (R) & 0.54 & 0.002 \\
Femoral rotation (L) & 0.77 & 0.001 \\
Tibial rotation (R) & 0.79 & 0.0001 \\
Tibial rotation (L) & 0.85 & 0.0001 \\
\hline
\end{tabular}

\section{Discussion}

We present data on the distribution of joint mobility in a large group of adolescents. It is clear that each joint has a normal distribution of mobility and that there is a distant, if statistically very significant, relationship between each of the joints we measured, apart from elbow extension.

We find this last measurement to be unreliable in the assessment of joint laxity, in contrast to Bird et al. ${ }^{4}$ who found it to be most reliable. We think that there are 2 reasons for this: first, uniquely among the joints we measured there is a bony stop in the joint when the olecranon enters its fossa, and secondly the measured angle may be affected by the muscle bulk of the triceps. We have tried putting the goniometer of the lateral side of the arm, but found it unreliable.

We describe methods of assessing hip and knee rotational mobility which correlate well with the other more established methods. We think these are easier to measure accurately than ankle dorsiflexion or knee extension. Knee extension was measured by the vector stereograph, which was the most accurate method we could find. This method may be considered too complex for clinical practice, though it is an extremely useful instrument for 3-dimensional measurements (see Pynsent et al. ${ }^{7}$ and Fairbank et al. ${ }^{6}$ for further discussion).

Joint mobility is normally distributed in our population, and this supports the concept that joint laxity is the extreme of the normal spectrum of joint mobility. ${ }^{8-10}$

A number of authors have recommended assessing joint laxity by the use of a scoring system. ${ }^{2-4}{ }^{11} 12$ Unfortunately the criteria that Carter and Wilkinson ${ }^{2}$ chose are arbitrary in the sense that they selected a population ranging from more than 3 standard deviations from the mean in the case of thumb abduction to less than one standard deviation in the case of knee extension. Beighton et al. ${ }^{3}$ are more consistent, using about 3 standard deviations from the mean in the joints that they selected, although we have shown elbow extension to be unreliable. We recommend that, in future studies involving joint mobility, quantitative measurements of joint movement are compared in test and control populations, as was recommended by Ansell. ${ }^{1}$ If a scoring system must be used, we would recommend 2 standard deviations from the mean as an appropriate criterion, as is the practice in other disciplines.

In clinical practice the most convenient joints for the assessment of joint mobility are thumb abduction and finger extension in the upper limb and hip and knee rotation in the lower limb. Joint laxity has been associated with a number of conditions, and adaptations of Carter and Wilkinson's methods are appropriate for its clinical assessment. Recently a number of conditions have been associated with joint hypomobility, including pulled muscles in American football players, ${ }^{13}$ juvenile onset diabetes, ${ }^{14}$ and, in this series, adolescent low back pain. ${ }^{5}$ Joint hypomobility can be identified only by quantitative techniques.

This work was funded by a grant from the East Anglian Regional Health Authority. We are grateful to the staff and pupils of the Hewitt School, Norwich, for their co-operation.

\section{References}

1 Ansell B M. Hypermobility of Joints Mod Trends Orthop 1972; 6: 25-39.

2 Carter C, Wilkinson J. Persistent joint laxity and congenital dislocation of the hip. J Bone Joint Surg 1964; 46B: 40-5.

3 Beighton P, Soloman L, Soskoine C L. Articular mobility in an African population. Ann Rheum Dis 1973; 32: 413-8.

4 Bird H A, Brodie D A, Wright V. Quantification of joint laxity. Rheumatol Rehabil 1979; 18: 161-6. 
5 Fairbank J C T, Pynsent P B, van Poortvliet J A, Phillips H. Influence of anthropometric factors and joint laxity on the incidence of adolescent back pain. Spine in press.

6 Fairbank J C T, Pynsent P B, van Poortvliet J A, Phillips H. Mechanical factors in the incidence of adolescent patellofemoral pain. In preparation.

7 Pynsent P B, Fairbank J C T, Clack F J, Phillips H. Computer recording of anatomical points in space.J Biomed Eng 1983; 5: 137-40.

8 Kirk J A, Ansell B M, Bywaters E G L. The hypermobility syndrome: musculoskeletal complaints associated with generalised joint hypermobility. Ann Rheum Dis 1967; 26: 419-25.

9 Anonymous. Leading article: Hypermobile joints. $\mathrm{Br}$ Med J 1968; i: 596.
10 Wood P H N. Is hypermobility a discrete entity? Proc $R$ Soc Med 1971; 64: 690-2.

11 Wynne-Davies R. A family study of Neonatal and late-diagnosis congenital dislocation of the hip. J Med Genet 1970; 7: 315-33.

12 Wynne-Davies R. Acetabular dysplasia and familial joint laxity: two aetiological factors in congenital dislocation of the hip. A review of 589 patients and their families.J Bone Joint Surg 1970; 52B: 701-16.

13 Nicholas J A. Injuries to knee ligaments: relationship to looseness and tightness in football players.JAMA 1970; 212: 2236-9.

14 Rosenblaum A L, Silverstein J H, Lezotte D C, Richardson K, McCallum M. Limited joint mobility in childhood diabetes mellitus indicates increased risk for microvascular disease. $N$ Engl $J$ Med 1981; 305: 191-4.

\section{Book review}

Chondromalacia of the Patella. Eds J. C. Rickett and E. L. Radin. Pp. 156. £23.00. Williams and Wilkins: Maryland, Baltimore. 1983.

This book records the proceedings of a symposium held in June 1981. In their introduction the editors claim that 'the Symposium was a watershed'. For once there seems to be some justification for this claim. The printed record contains many superb articles, and the discussion chapters are gems.

The organisers managed to get together most of those who have made major contributions to the field in recent years. They also addressed fundamental questions, such as the meaning of the word chondromalacia and the relationship between pathology and symptoms. Excellent contributions on pathology and healing of the articular cartilage by George Meachim, John Goodfellow, and Rudolph Lemperg are backed up by radiological, clinical, and biochemical contributions from Carroll Laurin, Ward Casscells, and David Hungerford respectively. The subsequent lively discussion led to several important conclusions. The group seemed to agree that the term 'chondromalacia' should be restricted to a description of soft cartilage, and that cartilage pathology has little or no relationship to symptoms. The preferred clinical term was 'anterior knee pain', and many expressed the opinion that a search for articular cartilage pathology in this syndrome was worthless. The important issues of whether or not cartilage lesions progress (some do and some don't, it seems), and whether disease starts on the surface or within the cartilage, were also discussed.

The second half of the book addresses therapy of anterior knee pain. Elegant descriptions of operative procedures by Paul Ficat, John Install, and Paul Maquet are marred a little by a lack of evidence for objectivity or controlled analyses of results. Eric Radin makes a plea for accurate diagnoses of the many possible causes of anterior knee pain and for a conservative approach. The concluding discussion session tackled some practical issues, such as whether or not sporting activities should be recommended in young, symptomatic patients, and to what extent patients should be investigated. What emerges is a refreshing new look at an old problem and an unusual willingness on the part of the experts to discard traditional views and dogma.

Rheumatologists may not want to buy a copy, but make sure that your library or your orthopaedic colleague has one, and take a look before getting depressed by the next young patient with that non-existent disease-'chondromalacia'. 